\title{
International trends in primary liver cancer incidence from 1973 to 2007
}

\author{
Yue Zhang ${ }^{1}$, Jian-Song Ren ${ }^{1}$, Ju-Fang Shi', Ni Li ${ }^{1}$, Yu-Ting Wang ${ }^{2}$, Chunfeng Qu ${ }^{2}$, Yawei Zhang ${ }^{1,3}$ and Min Dai ${ }^{1^{*}}$
}

\begin{abstract}
Background: Primary liver cancer (PLC) is a common cancer worldwide, especially in developing countries. Several previous studies using different datasets have summarized PLC incidence rates and trends in different populations. However, with changes in exposure to risk factors and the implementation of preventive measures, the epidemiology of PLC worldwide may have changed.

Methods: We extended the analyses using the latest data from Cancer Incidence in Five Continents over the 35-year period 1973-2007 from 24 populations in Americas, Asia, Europe and Oceania using Joinpoint regression analysis. We examined age-standardized rates (ASRs) of PLC by histologic subtypes for both males and females in 24 populations during the period 2003-2007.
\end{abstract}

Results: We found that during the period 2003-2007, the highest ASRs for PLC were observed in some Asian populations, ranging from 19.0 to 26.7 per 100,000 in males and 4.8 to 8.7 per 100,000 in females. The international trends between 1973 and 2007 showed that ASRs for PLC were declining in several Asian populations. In contrast, ASRs for PLC were increasing in some European, American and Oceanian populations.

Conclusions: Although the reasons were not fully clear for these trends, public health measures in Asian populations and HCV transmission in European, American and Oceanian populations were likely to have contributed to these patterns. Meanwhile, other possible risk factors such as the consumption of alcohol, obesity, and nonalcoholic fatty liver disease should also be concerned for the burden of PLC.

Keywords: Liver neoplasms, Incidence, International trends, HBV, HCV

\section{Background}

It was estimated that for the year 2012, primary liver cancer (PLC) incidence rates ranked fifth in men and ninth in women worldwide [1]. The number of incident cases of PLC was estimated to be 782,000 per year, including 554,000 in men and 228,000 in women [1]. PLC mortality rates ranked the second in both sexes in the world [1]. Five-year relative survival rate for USA tends to be $16.6 \%$ based on data from the Surveillance, Epidemiology, and End Results (SEER) (2004-2010) Program of the US National Cancer Institute [2]. In China, the age-standardized 5-year relative survival rate for liver cancer was $10.1 \%$ [3]. PLC is the major type of liver cancer, which is composed of several histologic

\footnotetext{
* Correspondence: daiminlyon@gmail.com

${ }^{1}$ National Office for Cancer Prevention and Control, Cancer Institute \& Hospital, Chinese Academy of Medical Sciences/Peking Union Medical College, Beijing 100021, China

Full list of author information is available at the end of the article
}

subtypes, including hepatocellular carcinoma (HCC), cholangiocarcinoma (CC), and combined hepatocellular carcinoma and cholangiocarcinoma (cHCC-CC) [4].

Most of the PLC cases (85\%) are diagnosed in developing countries. The highest incidence rates have been reported in the regions of Southeast Asia and subSaharan Africa [5]. In these high-incidence populations, except for Japan, chronic infection with hepatitis B virus (HBV) and aflatoxin exposure were recognized as major risk factors for PLC. In low-incidence populations, however, PLC was mainly associated to the chronic hepatitis $\mathrm{C}$ virus (HCV) infection. It was estimated that most HCC cases (approximately 80\%) were associated with $\mathrm{HBV}$ and/or HCV infections [6]. Moreover, some recent studies indicated that alcohol-related liver diseases, smoking, immigration, and obesity were also possible risk factors linking to PLC [7-9].

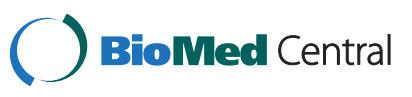

(c) 2015 Zhang et al.; licensee BioMed Central. This is an Open Access article distributed under the terms of the Creative Commons Attribution License (http://creativecommons.org/licenses/by/4.0), which permits unrestricted use, distribution, and reproduction in any medium, provided the original work is properly credited. The Creative Commons Public Domain Dedication waiver (http://creativecommons.org/publicdomain/zero/1.0/) applies to the data made available in this article, unless otherwise stated. 
Several previous studies [10-12] using different datasets had reported the international trends in PLC incidence rates, one of which [12] reported the global PLC incidence rates and trends for 1993-2002 (10-year period). However, with changes in exposure to risk factors and the implementation of protective measures, the epidemiology of PLC worldwide may have changed. To give a longer-term and more recent comprehensive picture on the current status of PLC worldwide, we extended the analyses for the 35-year period from 1973 to 2007 from 24 populations in Americas, Asia, Europe and Oceania. This data may provide more useful evidence for evaluating the effect of previous measures of PLC prevention and control, and may facilitate the development of future measures.

\section{Methods}

\section{Incidence data}

To examine the changing trends in the incidence of PLC over time, age-standardized (by Segi's world standard population [13]) incidence rates (ASRs) by sex were obtained from Volumes 4-10 of Cancer Incidence in Five Continents (CI5) from the website of the International Agency for Research on Cancer (IARC) [14-20] in which all data is publicly available. Volumes 4-10 of CI5 generally provided data by 5-year periods: 19731977, 1978-1982, 1983-1987, 1988-1992, 1993-1997, 1998-2002 and 2003-2007. Incidence data from 2003 to 2007 by histologic subtypes (HCC, CC, other \& unspecified carcinoma) were collected from 24 populations in four continents from Vol. 10 of CI5. Classification of PLC from Vols. 4, 5-8 and 9-10 of CI5 was coded according to the International Classification of Diseases (ICD) 8th (155), 9th (155) and 10th (C22) revisions, respectively.

Populations were chosen for inclusion in our study on the basis of the following criteria: (1) incidence for time periods at least as far back as 1983-1987; (2) an absence of changes in population coverage or of warnings regarding data quality reported in CI5 Vols. 4-10; and (3) a sufficiently large number of registered cases in CI5 Vol. 10 to enable analyses of recent rates by histologic subtypes (trends by histologic subtypes were not included in our study). Only one registry from each country was selected; if more than one registry met the basic criteria, the registry with the largest population was included in the analysis (expect for China which included Hong Kong and Shanghai). Twenty four populations were selected: four from the Americas (Canada, British Columbia [BC]; Colombia, Cali; USA, SEER: (9 registries: California: San Francisco; Connecticut; Georgia: Atlanta; Hawaii; Iowa; Michigan: Detroit; New Mexico; Utah; Washington: Seattle) Black/White), six from Asia (China, Hong Kong; China, Shanghai; India, Mumbai; Israel: Jews;
Japan, Osaka Prefecture; Singapore: Chinese), five from Northern Europe (Denmark; Finland; Norway; Sweden; UK, England, North Western Region [NWR]), three from Western Europe (France, Bas-Rhin; Germany, Saarland; Switzerland, Geneva), four from elsewhere in Europe [21] (Southern and Central \& Eastern Europe including Italy, Varese Province; Poland, Cracow; Slovakia; Spain, Navarra), and two from Oceania (Australia, New South Wales [NSW]; New Zealand). No African populations met all the inclusion criteria. However, four African populations (Algeria, Setif Wilaya; Egypt, Gharbiah; Uganda, Kyadondo; Zimbabwe, Harare: African) were chosen to describe the PLC incidence rates in the last time interval (2003-2007).

Incidence data for white and black populations in US were not included in CI5 vol. four (1973-1977) and vol. five (1978-1982), so we further referred to the US SEER dataset [22]. The SEER program is a population-based cancer registry system covering 18 registries and 28\% of the US population. Long-term data from 1973 to 2010 were available from nine registries that included approximately $9.4 \%$ of the US population (based on 2010 census).

For New Zealand, we abstracted the data for 1983-1987 and 1988-2002 from CI5plus [23] which was part of CI5 databases and contained annual incidence data for a single registry or a group of populations in one country. The data for the last time period 2003-2007 were obtained from CI5 vol. 10.

\section{Data analysis}

Incidence trends in ASRs of PLC were analyzed using Joinpoint regression (Joinpoint regression software, Version 3.5.3-May 2012, available through the Surveillance Research Program of the US National Cancer Institute). The permutation method was used for significance tests. Changes in annual incidence rates from PLC were calculated as annual percentage change (APC) in each segment. In the final model, the Joinpoint analysis provided average annual percentage change (AAPC). The significant test of APC and AAPC to 0 was also conducted.

Age-standardized incidence rates of PLC by histologic subtypes (HCC, CC and other \& unspecified carcinoma) and sex for selected populations during the period 2003-2007 were integrated and calculated. Secular trends in ASRs were examined by registry and sex for every fiveyear period during 1973-2007. PLC trends from New Zealand were described during five-year periods from 1983-1987 to 2003-2007. Figures displaying the incidence trends were prepared using a semi-log scale to facilitate the comparison of temporal trends as well as magnitude. These data were plotted at the midpoint of each five-year interval. 


\section{Results}

ASRs for PLC in 2003-2007 were highest in some populations of Asia (China, Hong Kong; Japan; China, Shanghai; Singapore: Chinese) and Africa (Egypt and Zimbabwe), and much lower in most populations in Europe, Americas and Oceania (Tables 1 and 2). In Asian populations, ASRs for PLC were ranging from 19.0 to 26.7 per 100,000 in males and 4.8 to 8.7 per 100,000 in females, except for India and Israel (Jews) (5.2 and 3.1 per 100,000 in males, 2.4 and 1.4 per 100,000 in females, respectively). In most populations in Americas, Europe and Oceania, PLC incidence rates varied between $2.2-7.8$ per 100,000 for males and 1.0-3.7 per 100,000 for females except for France (13.6 per 100,000 for males and 2.5 per 100,000 for females), Switzerland (13.1 per 100,000 for males and 3.0 per 100,000 for females), Italy (12.6 per 100,000 for males and 3.7 per 100,000 for females), and USA, Black population (11.6 per 100,000 for males and 3.1 per 100,000 for females).

Tables 1 and 2 also showed the results of Joinpoint analysis for ASRs in males and females for all ages, respectively. The secular trends in PLC incidence among 24 populations from 1973 to 2007 were presented in Figure 1. The increasing trends for both males and females in PLC incidence rates were seen in most of the populations in Europe, Americas, and Oceania. UK, England, France, Germany, Switzerland, Italy, Canada, Colombia, USA: Black, USA: White, Australia, and New Zealand (1982-2007) showed a significant increasing trend across all the periods (Tables 1 and 2 and Figure 1).

In males, ASRs for PLC in Germany, USA, Black, and USA, White increased significantly from the period 1982-1987 (Table 1 and Figure 1A). PLC incidence rates in France, Canada and Australia significantly increased from 1973-1977, leveled off in the 1990s (Table 1 and Figure 1A). ASRs for PLC in Spain significantly increased by $28.9 \%$ per year from $1973-1977$, significantly decreased by $1.8 \%$ per year from 1982-1987, whereas ASRs for PLC in Finland, Norway, Sweden, Poland and Slovakia leveled off in all the period (Table 1 and Figure 1A). In females, the pattern of PLC incidence in each population seemed to be similar except for Denmark, Poland and Spain (Table 2 and Figure 1B). ASRs for PLC in Poland significantly decreased by $3.1 \%$ per year from 1973-1977 to 2003-2007, whereas ASRs for PLC in Denmark and Spain showed stable trends from 1973-1977 to 2003-2007.

However, in Asia, ASRs for PLC for both males and females showed significant decreasing trends in two of the six populations (China, Shanghai; Singapore: Chinese) from 1973-1977 to 2003-2007 (Tables 1 and 2 and Figure $1 \mathrm{~A}$ and $\mathrm{B})$. The stable trends among males and females were seen in two of the six populations (China, Hong Kong and Israel: Jews) from 1973-2007 to 2003-
2007. ASRs for PLC in one of the six populations (Japan) significantly increased by $23.0 \%$ in males and $23.5 \%$ in females from 1973-1977 and reached a plateau in 1990s (Tables 1 and 2 and Figure $1 \mathrm{~A}$ and B). Whereas ASRs for PLC for females in India significantly increased by 5.3\% from 1973-1977 and leveled off in 1980s (Table 2 and Figure 1B).

According to the ASRs of PLC by histologic subtypes from 2003 to 2007, HCC was the leading histologic subtype, followed by CC and other \& unspecified carcinoma (Figure 2). The highest incidence rate of HCC was observed in China, Hong Kong (8.5 per 100,000 in males and 1.9 per 100,000 in females), and the lowest one was shown in UK England (0.9 per 100,000 in males and 0.3 per 100,000 in females). The highest incidence of CC was seen in France (2.0 per 100,000 in males and 0.7 per 100,000 in females), followed by other European countries including Spain (1.1 per 100,000 in males and 0.6 per 100,000 in females), Finland (1.0 per 100,000 in males and 0.7 per 100,000 in females), and Italy (1.0 per 100,000 in males and 0.6 per 100,000 in females). China, Hong Kong (0.9 per 100,000 in males and 0.7 per 100,000 in females) and Japan (0.9 per 100,000 in males and 0.5 per 100,000 in females) had relatively higher incidence of CC than other Asian countries.

\section{Discussion}

International trends in PLC incidence rates during the period 1973-2007 showed that the PLC incidence rates increased in most European, American and Oceanian populations, although these age-standardized PLC incidence rates in 2003-2007 were much lower than these in Asia. Meanwhile, PLC incidence rates decreased in Asian populations, although their age-standardized PLC incidence rates in 2003-2007 were the highest in the world.

PLC is a common cancer, particularly in Asia countries such as China, Japan and Singapore (Chinese). Among these countries, PLC is closely associated with hepatitis virus infection (HBV infection in China and Singapore, $\mathrm{HCV}$ infection in Japan) and exposure to aflatoxin (in China). In our study, the decreasing trends in China and Singapore may be attributed to some public health measures [24-27]. HBV vaccination was incorporated into the national childhood immunization program by China and Singapore from the middle 1980s to the early 1990s. The immunization coverage with three doses of HBV vaccine was $70.7 \%-95.0 \%$ in 1999 [28,29]. Several studies also reported the decreases in PLC incidence rates in China, particularly in Shanghai and in younger age groups $[24,30]$. Another study in Taiwan showed that the ageand sex-adjusted rate ratios for individuals aged 5 to 29 years decreased by more than $80 \%$ for HCC incidence from 1977-1980 to 2001-2004 [25]. In Singapore, Chia et al. [26] suggested that a general declining trend in liver 
Table 1 International variation in primary liver cancer incidence rates for males, from 1973-1977 to 2003-2007

\begin{tabular}{|c|c|c|c|c|c|c|c|c|c|c|c|}
\hline \multirow[t]{2}{*}{ Populations } & \multirow{2}{*}{$\begin{array}{l}\text { Period of registry } \\
\text { established }\end{array}$} & \multirow{2}{*}{$\begin{array}{l}\text { Mean } \\
\text { of } \mathrm{MV} \%{ }^{1}\end{array}$} & \multicolumn{2}{|l|}{ 1973-1977 } & \multicolumn{2}{|l|}{ 2003-2007 } & \multicolumn{5}{|c|}{ Joinpoint analyses (1973-2007) } \\
\hline & & & Cases & Rate $^{2}$ & Cases & Rate $^{2}$ & Trend 1 Period & Trend $2 \mathrm{APC}^{3}(\%)$ & Period & $\operatorname{APC}^{3}(\%)$ & $\operatorname{AAPC}^{4}(\%)$ \\
\hline \multicolumn{12}{|l|}{ Northern Europe } \\
\hline \multirow[t]{2}{*}{ Denmark } & 1953-1957 & 88.0 & 424 & 2.9 & 947 & 4.1 & 1975-2005 & $0.8^{\#}$ & & & $0.8^{\#}$ \\
\hline & & & (1973-1976) & & & & & & & & \\
\hline \multirow[t]{2}{*}{ Finland } & 1959-1961 & 88.3 & 473 & 3.2 & 1,192 & 5.2 & 1975-2005 & 1.2 & & & 1.2 \\
\hline & & & $(1971-1976)$ & & & & & & & & \\
\hline Norway & 1959-1961 & 85.7 & 230 & 1.6 & 421 & 2.2 & $1975-2005$ & 0.8 & & & 0.8 \\
\hline \multirow[t]{2}{*}{ Sweden } & 1959-1961 & 95.7 & 1,162 & 3.4 & 1,465 & 3.4 & $1975-2005$ & -0.7 & & & -0.7 \\
\hline & & & $(1971-1975)$ & & & & & & & & \\
\hline UK, England, NWR & 1973-1977 & 44.7 & 157 & 1.1 & 1,250 & 4.4 & 1975-1985 & $6.0^{\#}$ & $1985-2005$ & $3.9^{\#}$ & $4.6^{\#}$ \\
\hline \multicolumn{12}{|l|}{ Western Europe } \\
\hline \multirow[t]{2}{*}{ France, Bas-Rhin } & 1975-1977 & 64.1 & 76 & 4.9 & 547 & 13.6 & 1975-1990 & $6.4^{\#}$ & 1990-2005 & 0.5 & $3.4^{\#}$ \\
\hline & & & $(1975-1977)$ & & & & & & & & \\
\hline Germany, Saarland & 1968-1972 & $64.5^{\mathrm{a}}$ & 86 & 2.4 & 394 & 7.5 & 1975-1985 & 4.6 & $1985-2005$ & $3.6^{\#}$ & $3.9^{\#}$ \\
\hline Switzerland, Geneva & 1970-1972 & 70.3 & 100 & 9.7 & 214 & 13.1 & $1975-2005$ & $0.9^{\#}$ & & & $0.9^{\#}$ \\
\hline \multicolumn{12}{|l|}{ Europe, Other } \\
\hline \multirow[t]{2}{*}{ Italy, Varese Province } & 1976-1977 & 55.5 & 64 & 6.9 & 516 & 12.6 & $1975-2005$ & $2.6^{\#}$ & & & $2.6^{\#}$ \\
\hline & & & $(1976-1977)$ & & & & & & & & \\
\hline \multirow[t]{2}{*}{ Poland, Cracow } & 1965-1966 & 42.3 & 89 & 5.9 & 103 & 4.8 & $1975-2005$ & -1.5 & & & -1.5 \\
\hline & & & & & $(2003-2006)$ & & & & & & \\
\hline Slovakia & 1973-1977 & 55.1 & 183 & 3.1 & 1,052 & 6.4 & $1975-2005$ & 2.6 & & & 2.6 \\
\hline Spain, Navarra & 1973-1977 & 51.2 & 8 & 0.5 & 217 & 7.8 & 1975-1985 & $28.9^{\#}$ & $1985-2005$ & $-1.8^{\#}$ & $7.5^{\#}$ \\
\hline \multicolumn{12}{|l|}{ Americas } \\
\hline Canada, BC & 1969-1972 & 56.5 & 142 & 2.0 & 201 & 5.2 & 1975-1995 & $3.7^{\#}$ & 1995-2005 & 2.3 & $3.3^{\#}$ \\
\hline \multirow[t]{2}{*}{ Colombia, Cali } & 1967-1971 & 71.8 & 22 & 1.9 & 178 & 4.2 & $1975-2005$ & $2.1^{\#}$ & & & $2.1^{\#}$ \\
\hline & & & (1972-1976) & & & & & & & & \\
\hline USA, SEER: Black & 1973-1975 & $78.0^{\mathrm{b}}$ & $154^{c}$ & 4.4 & 936 & 11.6 & 1975-1985 & 1.2 & $1985-2005$ & $4.1^{\#}$ & $3.1^{\#}$ \\
\hline USA, SEER: White & 1973-1975 & $74.7^{b}$ & $1,009^{c}$ & 2.1 & 4,443 & 5.9 & 1975-1985 & 1.4 & $1985-2005$ & $4.6^{\#}$ & $3.5^{\#}$ \\
\hline \multicolumn{12}{|l|}{ Oceania } \\
\hline Australia, NSW & 1973-1977 & 73.8 & 139 & 1.1 & 1,379 & 5.4 & 1975-1995 & $6.5^{\#}$ & 1995-2005 & 4.4 & $5.8^{\#}$ \\
\hline New Zealand & $1962-1966$ & $61.1^{d}$ & - & - & 738 & 5.2 & $1985-2005$ & $3.3^{\#}$ & & & $3.3^{\#}$ \\
\hline
\end{tabular}


Table 1 International variation in primary liver cancer incidence rates for males, from 1973-1977 to 2003-2007 (Continued)

Asia

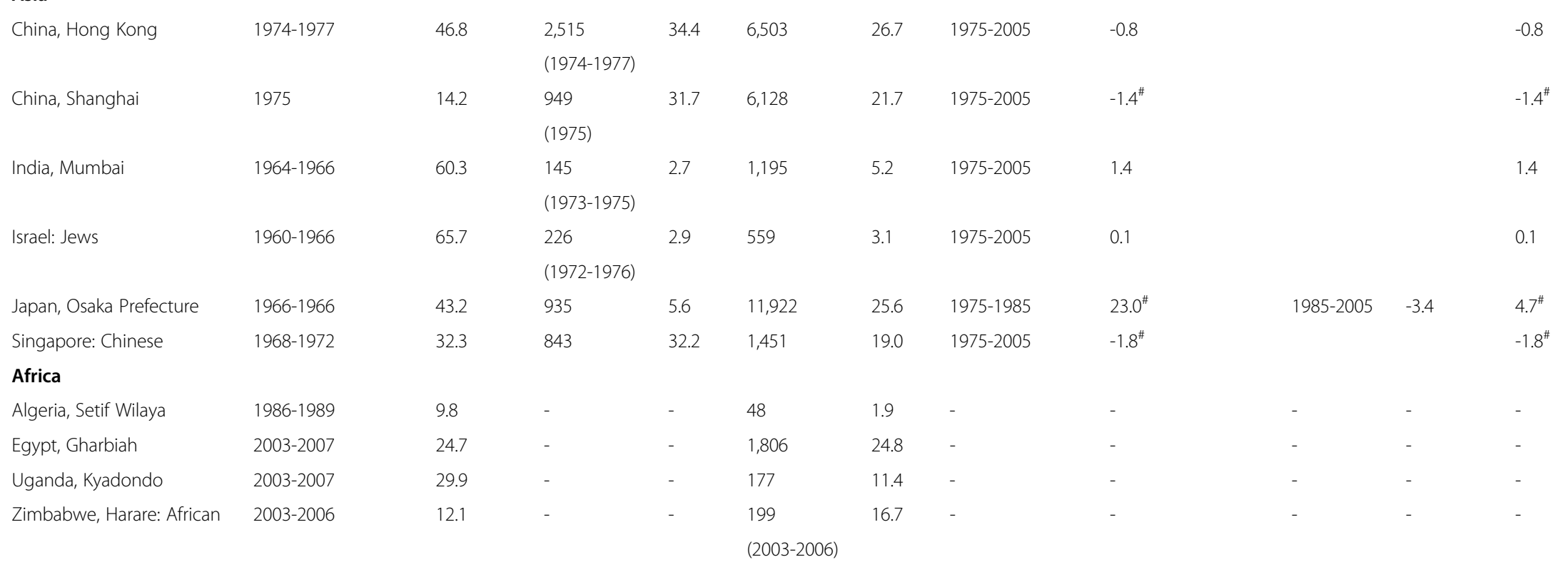

${ }^{1}$ Mean of MV\% (Percentage of morphologically verified cases) was calculated from 1978 to $2007 .{ }^{2}$ Rate is age-standardized to the world population, per 100,000 person-years. ${ }^{3} \mathrm{APC}$, Annual Percent Change. ${ }^{4} \mathrm{AAPC}$, Average Annual Percent Change. ${ }^{\# A P C / A A P C}$ is significantly different from 0 (two-side $p<0.05$ ).

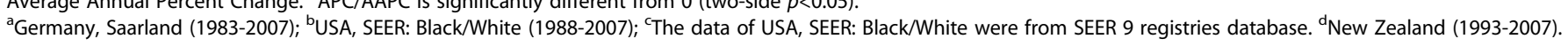


Table 2 International variation in primary liver cancer incidence rates for females, from 1973-1977 to 2003-2007

\begin{tabular}{|c|c|c|c|c|c|c|c|c|c|c|c|}
\hline \multirow[t]{2}{*}{ Populations } & \multirow{2}{*}{$\begin{array}{l}\text { Period of registry } \\
\text { established }\end{array}$} & \multirow{2}{*}{$\begin{array}{l}\text { Mean } \\
\text { of MV\% }{ }^{1}\end{array}$} & \multicolumn{2}{|l|}{ 1973-1977 } & \multicolumn{2}{|l|}{ 2003-2007 } & \multicolumn{5}{|c|}{ Joinpoint analyses (1973-2007) } \\
\hline & & & Cases & Rate $^{2}$ & Cases & Rate $^{2}$ & Trend 1 Period & Trend $2 \mathrm{APC}^{3}(\%)$ & Period & $\operatorname{APC}^{3}(\%)$ & $\operatorname{AAPC}^{4}(\%)$ \\
\hline \multicolumn{12}{|l|}{ Northern Europe } \\
\hline \multirow[t]{2}{*}{ Denmark } & 1953-1957 & 82.8 & 308 & 1.6 & 434 & 1.6 & 1975-2005 & -0.4 & & & -0.4 \\
\hline & & & $(1973-1976)$ & & & & & & & & \\
\hline \multirow[t]{2}{*}{ Finland } & 1959-1961 & 82.1 & 391 & 1.7 & 701 & 2.1 & 1975-2005 & 0.1 & & & 0.1 \\
\hline & & & $(1971-1976)$ & & & & & & & & \\
\hline Norway & 1959-1961 & 78.2 & 117 & 0.6 & 240 & 1.0 & 1975-2005 & 1.0 & & & 1.0 \\
\hline \multirow[t]{2}{*}{ Sweden } & 1959-1961 & 94.3 & 754 & 1.8 & 859 & 1.7 & 1975-2005 & -1.1 & & & -1.1 \\
\hline & & & $(1971-1975)$ & & & & & & & & \\
\hline UK, England, NWR & 1973-1977 & 38.4 & 75 & 0.4 & 863 & 2.3 & 1975-2005 & $5.3^{\#}$ & & & $5.3^{\#}$ \\
\hline \multicolumn{12}{|l|}{ Western Europe } \\
\hline \multirow[t]{2}{*}{ France, Bas-Rhin } & 1975-1977 & 56.4 & 18 & 0.7 & 133 & 2.5 & 1975-2005 & $3.9^{\#}$ & & & $3.9^{\#}$ \\
\hline & & & $(1975-1977)$ & & & & & & & & \\
\hline Germany, Saarland & 1968-1972 & $54.4^{\mathrm{a}}$ & 77 & 1.5 & 207 & 2.9 & $1975-2005$ & $2.0^{\#}$ & & & $2.0^{\#}$ \\
\hline Switzerland, Geneva & 1970-1972 & 66.9 & 23 & 1.3 & 66 & 3.0 & $1975-2005$ & $2.4^{\#}$ & & & $2.4^{\#}$ \\
\hline \multicolumn{12}{|l|}{ Europe, Other } \\
\hline \multirow[t]{2}{*}{ Italy, Varese Province } & 1976-1977 & 48.9 & 37 & 2.7 & 224 & 3.7 & 1975-2005 & $1.0^{\#}$ & & & $1.0^{\#}$ \\
\hline & & & $(1976-1977)$ & & & & & & & & \\
\hline \multirow[t]{2}{*}{ Poland, Cracow } & 1965-1966 & 32.2 & 116 & 4.3 & 70 & 2.4 & $1975-2005$ & $-3.1^{\#}$ & & & $-3.1^{\#}$ \\
\hline & & & & & $(2003-2006)$ & & & & & & \\
\hline Slovakia & 1973-1977 & 52.2 & 190 & 2.6 & 619 & 2.4 & 1975-2005 & 0.6 & & & 0.6 \\
\hline Spain, Navarra & 1973-1977 & 38.1 & 11 & 0.6 & 89 & 2.2 & 1975-2005 & 1.4 & & & 1.4 \\
\hline \multicolumn{12}{|l|}{ Americas } \\
\hline Canada, BC & 1969-1972 & 52.6 & 87 & 1.1 & 97 & 1.7 & $1975-2005$ & $1.2^{\#}$ & & & $1.2^{\#}$ \\
\hline \multirow[t]{2}{*}{ Colombia, Cali } & 1967-1971 & 72.5 & 19 & 1.5 & 182 & 3.2 & 1975-1985 & 1.6 & $1985-2005$ & $3.4^{\#}$ & $2.8^{\#}$ \\
\hline & & & $(1972-1976)$ & & & & & & & & \\
\hline USA, SEER: Black & 1973-1975 & $72.1^{\mathrm{b}}$ & $68^{c}$ & 1.5 & 336 & 3.1 & 1975-1985 & 0.7 & 1985-2005 & $3.2^{\#}$ & $2.4^{\#}$ \\
\hline USA, SEER: White & 1973-1975 & $71.0^{\mathrm{b}}$ & $613^{c}$ & 1.0 & 1,762 & 1.9 & 1975-1985 & 0.7 & $1985-2005$ & $3.0^{\#}$ & $2.2^{\#}$ \\
\hline \multicolumn{12}{|l|}{ Oceania } \\
\hline Australia, NSW & 1973-1977 & 71.7 & 56 & 0.4 & 634 & 1.9 & 1975-1990 & 3.6 & 1990-2005 & $7.7^{\#}$ & $5.6^{\#}$ \\
\hline New Zealand & 1962-1966 & $55.2^{d}$ & - & - & 328 & 1.9 & 1985-2005 & $2.8^{\#}$ & & & $2.8^{\#}$ \\
\hline
\end{tabular}


Table 2 International variation in primary liver cancer incidence rates for females, from 1973-1977 to 2003-2007 (Continued)

Asia

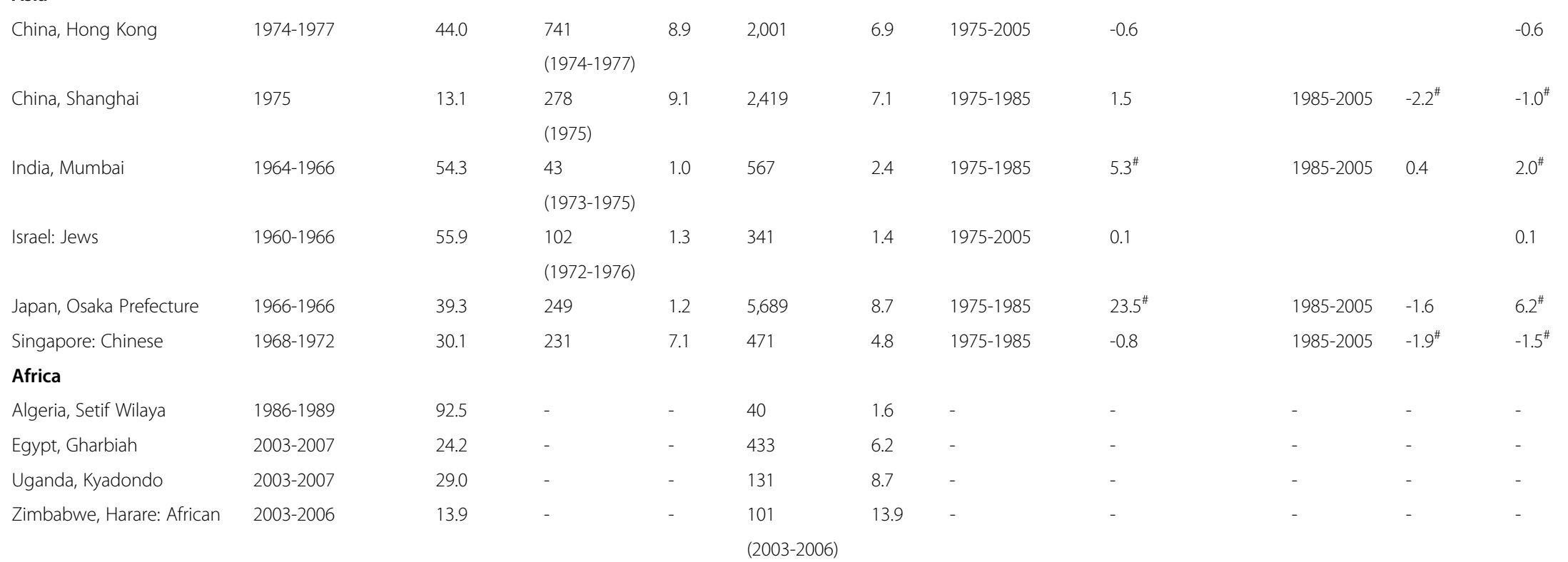

${ }^{1}$ Mean of MV\% (Percentage of morphologically verified cases) was calculated from 1978 to $2007 .{ }^{2}$ Rate is age-standardized to the world population, per 100,000 person-years. ${ }^{3}$ APC, Annual Percent Change. ${ }^{4}$ AAPC, Average Annual Percent Change. "APC/AAPC is significantly different from 0 (two-side $p<0.05$ ).

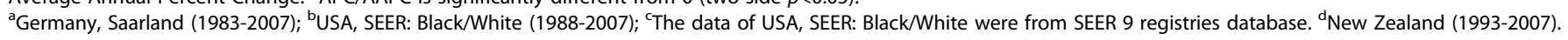



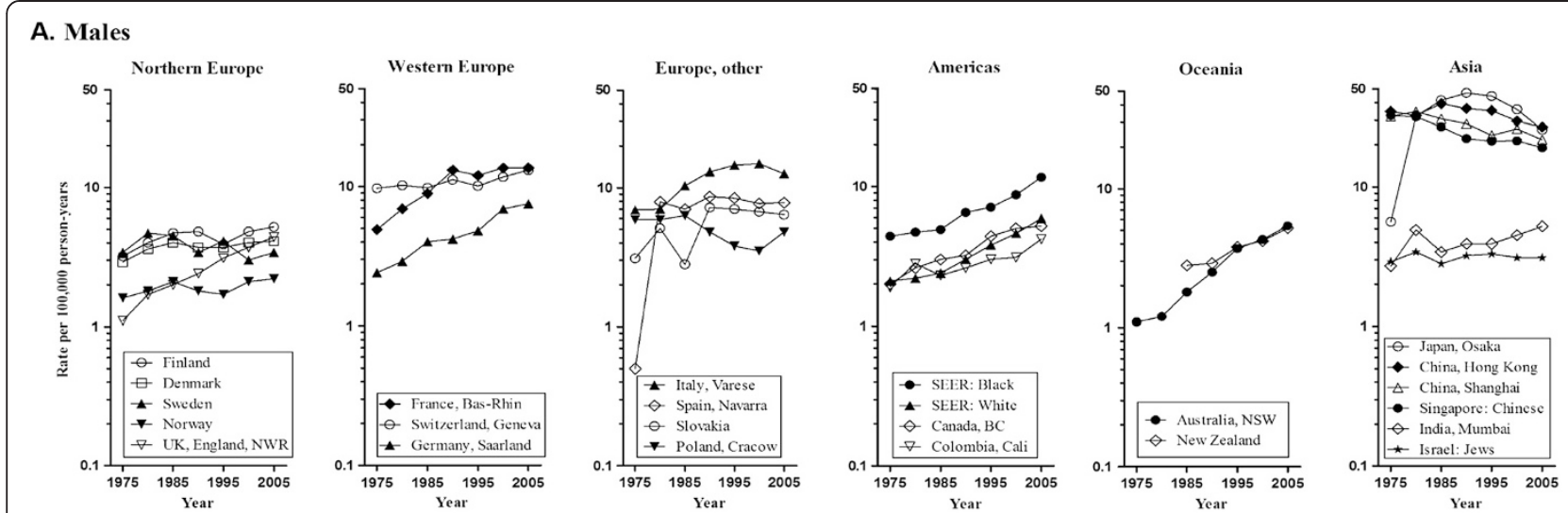

B. Females
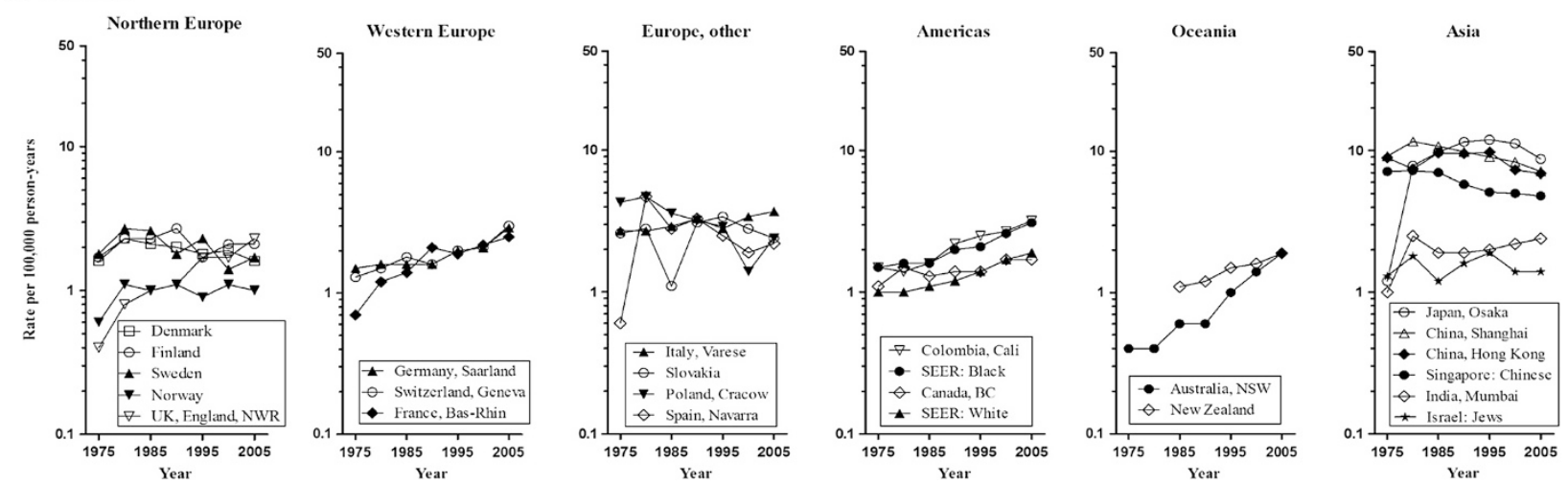

Figure 1 Trends in age-standardized primary liver cancer incidence rates by continent and area for the time period 1973-2007: A. Males B. Females.

cancer incidence was especially notable in local-born Chinese. Although the measure had no an effect on general population, we expect it will play an important role in the reduction of PLC incidence rates in the coming decades. Moreover, dietary aflatoxin exposure declined in the high-incidence areas of PLC seemed to have contributed to the decrease in PLC incidence in China [31]. A study in Qidong, China [31], where aflatoxin exposures were common, had reported that the decreasing liver cancer incidence in population over 25 years could mainly be attributable to the reduction of exposure to aflatoxin from 1980 to 2008.

In Japan, there were different trends between 19731992 and 1988-2007. The increasing trends started in 1973-1977 and reached peak in 1988-1992. This was thought to be in part due to the spread of HCV infection, which began in the 1920s and increase after World War II with an explosion in parenteral amphetamine use and paid blood donation [32,33]. Although APC did not significantly decrease during 1988-2007, the decline in PLC incidence had been continuously seen from 19881992 in our analysis. Stiffening of legal penalties against amphetamine use starting in 1954 and conversion from paid to voluntary blood donation in late 1960s might have reduced HCV transmission [34]. After the discovery of HCV RNA, HCV screening tests for first- and second-generation HCV antibodies started in 1989 and 1992, respectively [35]. These tests were adopted by the Red Cross Blood Center for screening blood, which further decreased the risk of post-transfusion hepatitis. The Japanese government has taken urgent comprehensive countermeasures against hepatitis ( $\mathrm{HBV}$ and $\mathrm{HCV}$ ) and HCC since 2002 [33]. Therefore, these measures would provide a significant contribution to decrease the number of patients suffering from HCV-related liver diseases including PLC.

In contrast, PLC was not a very common cancer in European, American and Oceanian countries where there were no epidemic regions of HBV infection. However, an increasing trend of PLC incidence rates was seen in most of these populations which were partly due to the widespread $\mathrm{HCV}$ infection associated with drug use, exposure to contaminated blood transfusion and/or needles used for medical purposes [36]. The natural history of PLC indicated that the time between exposure to $\mathrm{HCV}$ and development of HCC is about 30 years [37]. HCV infections were found in $30-50 \%$ of $\mathrm{HCC}$ patients in the United States and 44-66\% of HCC patients in Italy [38]. Both of 


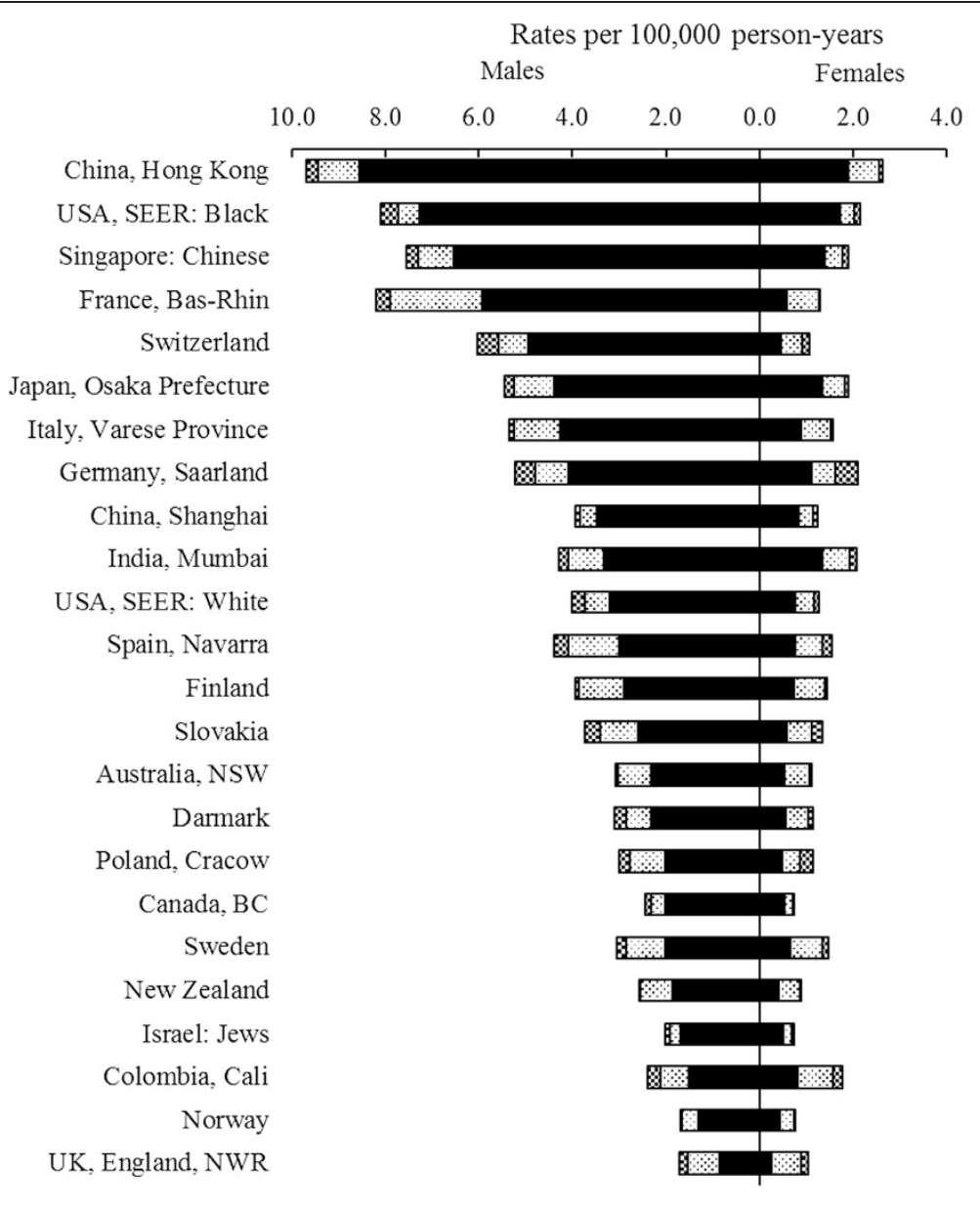

- Hepatocellular carcinoma $₫$ Cholangiocarcinoma o Other \& Unspecified carcinoma

Figure 2 Age-standardized primary liver cancer incidence rates by histologic subtypes for selected populations for the time period 2003-2007.

these countries had the highest PLC incidence rates in their own continent. The different peak years of $\mathrm{HCV}$ infection prevalence for each country were likely responsible for the respective peaks in PLC incidence rates. The increasing trends in PLC incidence rates in the United States could be attributed to increased HCV exposures by contact with contaminated blood and injection drug use during the 1960s and 1970s [39]. In Italy, the upsurge of liver cancer incidence after 1970s was in part attributable to $\mathrm{HCV}$ infection caused by the re-use of disposable syringes among intravenous drug users without proper disinfection [40]. Meanwhile, in several studies conducted in Western countries, 30 to $40 \%$ of patients with HCC did not have chronic infection with $\mathrm{HBV}$ or $\mathrm{HCV}$, suggesting alternative causes [5]. Other factors including alcohol $[41,42]$, obesity $[43,44]$, and non-alcoholic fatty liver disease (NAFLD) [5] might be contributed to the increasing trend. In population-based cohort studies in the United States and Scandinavia [44-46], HCC was 1.5 to 2.0 times as likely to develop in obese persons as in those who were not obese. NAFLD, which is present in up to $90 \%$ of all obese persons and up to $70 \%$ of persons with type 2 diabetes, has been proposed as a possible risk factor for HCC [47]. Although there were still some difficult problems in the latency period from exposure to these factors and PLC development, more emphasis should be recommended to control these factors.

The advent of precise diagnostic tests may increase recognition of the disease, which accounts for a rising incidence, rather than a true increase in its occurrence [48]. Ultrasonography, measurement of serum alphafetoprotein, and computed tomography scanning have been routinely used since the early 1980s, which should lead to an increase in the number of hepatic biopsies conducted. However, the percentage of histologically confirmed PLC has not increased significantly during the study period in these countries which had an increasing trend in PLC incidence rates. In addition, females in 
Poland (from 1973-1977 to 2003-2007) and males in Spain (from 1982-1987 to 2003-2007) also exhibited a decreasing trend of PLC incidence rates. The reasons for this decreasing trend remain unclear.

This study has several strengths. The data were abstracted from large, well-established registries throughout the world. For the first time, data covering 35 years were analyzed to describe the variation of international trends in PLC incidence rates, which may stimulate further etiologic research. In addition, incidence rates for particular histologic subtypes of PLC in different populations were examined separately. One limitation of this study was that trends by histologic subtypes were not examined. The variation of ICD coding might influence the interpretation of our results. In our study, ICD coding contained ICD-8 (Malignant neoplasm of liver and intrahepatic bile ducts, specified as primary), ICD-9 (Malignant neoplasm of liver, specified as primary) and ICD-10 (Malignant neoplasm of liver and intrahepatic bile ducts, specified as primary). CC was not included in ICD-9 (period from 1978-1982 to 1993-1997). Therefore, the changes in PLC rates mainly reflect changes of HCC. Our study was also limited by the lack of nationwide cancer registries in some countries, thus registration data might not accurately reflect the true patterns in the respective countries.

\section{Conclusions}

Our analysis on CI5 data suggested that ASRs for PLC were declining in several Asian countries where the highest incidence rates were still seen between 1973 to 1977 and 2003 to 2007. On the contrary, ASRs for PLC were increasing in some American, European and Oceanian countries. HBV vaccination programs and screening tests might play an important role in deceasing trends in Asia. Although the reasons of the increasing trends in American, European and Oceanian populations were not fully clear, the variation was likely to be due to in part the increasing prevalence of $\mathrm{HCV}$ infection. While a vaccine for HBV is widely available in most developed and developing countries, there is currently no vaccine available for $\mathrm{HCV}$. Therefore, it is a critical for HCV infection prevention that blood donations are screened, safe injection practices are used at all times, and unnecessary injections are avoided. Additionally, controlling other risk factors such as alcohol consumption, obesity, and NAFLD may help to reduce PLC incidence rates.

\footnotetext{
Abbreviations

PLC: Primary liver cancer; SEER: Surveillance, Epidemiology, and End Results; HCC: Hepatocellular carcinoma; CC: Cholangiocarcinoma; CHCC-CC: Combined hepatocellular carcinoma and cholangiocarcinoma; ASRs: Age-standardized incidence rates; HBV: Hepatitis B virus; HCV: Hepatitis C virus; Cl5: Cancer Incidence in Five Continents; IARC: International Agency for Research on Cancer; ICD: International Classification of Diseases; BC: British Columbia; NWR: North Western Region; NSW: New South Wales; APC: Annual percentage
}

change; AAPC: Average annual percentage change; HBsAg: Hepatitis B surface antigen; NAFLD: Nonalcoholic fatty liver disease.

\section{Competing interests}

The authors declare that they have no competing interests.

\section{Authors' contributions}

YZ participated in acquisition of data, analysis and interpretation of data and drafted the manuscript. JSR participated in acquisition of data, analysis and interpretation of data and revised the manuscript. MD participated in the design of study, acquisition of data, analysis and interpretation of data and revised the manuscript. JFS, NL, YTW, CFQ and YWZ gave some substantial comments to draft the manuscript. All authors read and approved the final manuscript.

\section{Acknowledgements}

We are very grateful to Rong-Shou Zheng and Si-Wei Zhang from National Office for Cancer Prevention and Control, Cancer Institute \& Hospital, Chinese Academy of Medical Sciences for providing us with valuable opinions and suggestions for data collection. We sincerely thank Ms. Catherine Lerro (Yale School of Public Health) for language proof reading. This study was funded by the State Key Projects Specialized for Infectious Diseases (No. 2008ZX10002008-001) and the Research Special Fund for Public Welfare Industry of Health (No. 201402003). The grant sponsors had no role in the study design, data collection, data analysis, data interpretation, or the writing of the manuscript.

\section{Author details}

${ }^{1}$ National Office for Cancer Prevention and Control, Cancer Institute \& Hospital, Chinese Academy of Medical Sciences/Peking Union Medical College, Beijing 100021, China. ${ }^{2}$ State Key Laboratory of Molecular Oncology, Cancer Institute \& Hospital, Chinese Academy of Medical Sciences, Beijing 100021, China. ${ }^{3}$ Yale School of Public Health, Yale School of Medicine, Yale Cancer Center, New Haven, CT 06510, USA.

Received: 14 May 2014 Accepted: 23 February 2015

Published online: 04 March 2015

\section{References}

1. Ferlay J, Soerjomataram I, Ervik M, Dikshit R, Eser S, Mathers C, Rebelo M, Parkin DM, Forman D, Bray F. GLOBOCAN 2012 v1.0, Cancer Incidence and Mortality Worldwide: IARC CancerBase No. 11 [Internet]. Lyon, France: International Agency for Research on Cancer; 2013. Available from: http://globocan.iarc.fr, accessed on 20/01/2014.

2. National Cancer Institute. Surveillance, Epidemiology, and End Results Program http://seer.cancer.gov/statfacts/html/livibd.html (accessed on 28/10/2014).

3. Zeng H, Zheng R, Guo Y, Zhang S, Zou X, Wang N, et al. Cancer survival in China, 2003-2005: A population-based study. Int J Cancer. 2015;136(8):1921-30

4. Tang D, Nagano H, Nakamura M, Wada H, Marubashi S, Miyamoto A, et al. Clinical and pathological features of Allen's type C classification of resected combined hepatocellular and cholangiocarcinoma: a comparative study with hepatocellular carcinoma and cholangiocellular carcinoma. J Gastrointest Surg. 2006;10(7):987-98.

5. El-Serag HB. Hepatocellular Carcinoma. N Engl J Med. 2011;365:1118-27.

6. El-Serag HB. Epidemiology of viral hepatitis and hepatocellular carcinoma. Gastroenterology. 2012;142(6):1264-73.

7. Shih WL, Chang HC, Liaw YF, Lin SM, Lee SD, Chen PJ, et al. Influences of tobacco and alcohol use on hepatocellular carcinoma survival. Int I Cancer. 2012;131(11):2612-21.

8. Ezzati M, Riboli E. Behavioral and dietary risk factors for noncommunicable diseases. N Engl J Med. 2013;369(10):954-64.

9. Chuang SC, La Vecchia C, Boffetta P. Liver cancer: descriptive epidemiology and risk factors other than HBV and HCV infection. Cancer Lett. 2009;286(1):9-14.

10. Nordenstedt $\mathrm{H}$, White DL, El-Serag HB. The changing pattern of epidemiology in hepatocellular carcinoma. Dig Liver Dis. 2010;42:S206-14.

11. McGlynn KA, Tsao L, Hsing AW, Devesa SS, Fraumeni JFJ. International trends and patterns of primary liver cancer. Int J Cancer. 2001;94(2):290-6.

12. Center MM, Jemal A. International trends in liver cancer incidence rates. Cancer Epidemiol Biomarkers Prev. 2011;20(11):2362-8.

13. Segi M. Cancer mortality for selected sites in 24 countries (1950-57). Sendai: Tohuku University School of Public Health; 1960.

14. Waterhouse J, Muir CS, Shanmugaratnam K, Powell J. Cancer Incidence in Five Continents, Vol. IVIARC Scientific Publications No. 42, Lyon, IARC. 1982. 
15. Muir CS, Waterhouse J, Mack T, Powell J, Whelan SL. Cancer Incidence in Five Continents, Vol. V. IARC Scientific Publications No. 88, Lyon, IARC. 1987.

16. Parkin DM, Muir CS, Whelan SL, Gao Y-T, Ferlay J, Powell J. Cancer Incidence in Five Continents, Vol. VI. IARC Scientific Publications No. 120, Lyon, IARC. 1992.

17. Parkin DM, Whelan SL, Ferlay J, Raymond L, Young J. Cancer Incidence in Five Continents, Vol. VII. IARC Scientific Publications No. 143, Lyon, IARC. 1997.

18. Parkin DM, Whelan SL, Ferlay J, Teppo L, Thomas DB. Cancer Incidence in Five Continents, Vol. VIII. IARC Scientific Publications No. 155, Lyon, IARC. 2002.

19. Curado MP, Edwards B, Shin HR, Storm H, Ferlay J, Heanue M, et al. Cancer Incidence in Five Continents, Vol. IX. IARC Scientific Publications No. 160, Lyon, IARC. 2007.

20. Forman D, Bray F, Brewster DH, Gombe Mbalawa C, Kohler B, Piñeros M, et al. Cancer Incidence in Five Continents, Vol. X (electronic version). Lyon, IARC. http://ci5.iarc.fr last accessed on [28/10/2013]. 2013.

21. Lortet-Tieulent J, Renteria E, Sharp L, Weiderpass E, Comber H, Baas P, et al. Convergence of decreasing male and increasing female incidence rates in major tobacco-related cancers in Europe in 1988-2010. Eur J Cancer. 2013; http://dx.doi.org/10.1016/j.ejca.2013.10.014

22. Surveillance, Epidemilology, and End Results (SEER) Program (November 2012 submission). Public use database (1973-1982). Surveillance Research Program, National Cancer Institute SEER*Stat software (seer.cancer.gov/ seerstat) version < Version 8.0.4>, Released April 15, 2013.

23. Ferlay J, Parkin DM, Curado MP, Bray F, Edwards B, Shin HR, et al. Cancer Incidence in Five Continents, Volumes I to IX: IARC CancerBase No. 9 [Internet]. International Agency for Research on Cancer: Lyon, France; 2010. Available from: http://ci5.iarc.fr.

24. Jin F, Devesa SS, Chow WH, Zheng W, Ji BT, Fraumeni JF, et al. Cancer incidence trends in urban Shanghai, 1972-1994: an update. Int J Cancer. 1999;83(4):435-40.

25. Chiang CJ, Yang YW, You SL, Lai MS, Chen CJ. Thirty-Year Outcomes of the National Hepatitis B Immunization Program in Taiwan. JAMA. 2013;310(9):974-6.

26. Chia KS, Lee HP, Lee J. Incidence of primary liver cancer in Singapore, 1968-1982. Ann Acad Med Singapore. 1989;18(3):313-6.

27. Lu W, Zheng Y. Prevalence and prevention measure of cancer in Shanghai. China Cancer. 2009;18:90-1.

28. Liang $X, B i$ S, Yang W, Wang L, Cui G, Cui F, et al. Epidemiological serosurvey of hepatitis $B$ in China-declining $\mathrm{HBV}$ prevalence due to hepatitis B vaccination. Vaccine. 2009;27(47):6550-7.

29. Ang LW, Cutter J, James L, Goh KT. Seroepidemiology of hepatitis B virus infection among adults in Singapore: a 12-year review. Vaccine. 2013;32(1):103-10

30. Gao S, Yang WS, Bray F, Va P, Zhang W, Gao J, et al. Declining rates of hepatocellular carcinoma in urban Shanghai: incidence trends in 1976-2005. Eur J Epidemiol. 2012;27(1):39-46.

31. Sun Z, Chen T, Thorgeirsson SS, Zhan Q, Chen J, Park JH, et al. Dramatic reduction of liver cancer incidence in young adults: 28 year follow-up of etiological interventions in an endemic area of China. Carcinogenesis. 2013;34(8):1800-5

32. Yoshizawa $\mathrm{H}$. Hepatocellular carcinoma associated with hepatitis $\mathrm{C}$ virus infection in Japan: projection to other countries in the foreseeable future. Oncology. 2002;62 Suppl 1:8-17.

33. Tsukuma H. Liver cancer and its prevention. Asian Pac J Cancer Prev. 2005;6:244-50

34. Hideo T, Yasuharu I, Naoki H, Yuri I, Kazuho I, Masahide O, et al. Declining Incidence of Hepatocellular Carcinoma in Osaka, Japan, from 1990 to 2003. Ann Intern Med. 2008;148:820-6.

35. Chung $H$, Ueda $T$, Kudo M. Changing trends in hepatitis $C$ infection over the past 50 years in Japan. Intervirology. 2010;53(1):39-43.

36. Jemal A, Center MM, DeSantis C, Ward EM. Global patterns of cancer incidence and mortality rates and trends. Cancer Epidemiol Biomarkers Prev. 2010;19(8):1893-907.

37. Kiyosawa K, Sodeyama T, Tanaka E, Gibo Y, Yoshizawa K, Nakano Y, et al. Interrelationship of blood transfusion, non-A, non-B hepatitis and hepatocellular carcinoma: analysis by detection of antibody to hepatitis $C$ virus. Hepatology. 1990;12:671-5.

38. El-Serag HB, Rudolph KL. Hepatocellular carcinoma: epidemiology and molecular carcinogenesis. Gastroenterology. 2007;132(7):2557-76.

39. Bosch FX, Ribes J, Díaz M, Cléries R. Primary liver cancer: Worldwide incidence and trends. Gastroenterology. 2004;127(5):S5-16.
40. Maso LD, Lise M, Zambon P, Crocetti E, Serraino D, Ricceri F, et al Incidence of primary liver cancer in Italy between 1988 and 2002: an age-period-cohort analysis. Eur J Cancer. 2008;44(2):285-92.

41. Donato F, Tagger A, Gelatti U, Parrinello G, Boffetta P, Albertini A, et al. Alcoho and hepatocellular carcinoma: the effect of lifetime intake and hepatitis virus infections in men and women. Am J Epidemiol. 2002;155(4):323-31.

42. Carlo LV. Alcohol and liver cancer. Eur J Cancer Prev. 2007;16(6):495-7.

43. Larsson SC, Wolk A. Overweight, obesity and risk of liver cancer: a metaanalysis of cohort studies. Brit J Cancer. 2007;97(7):1005-8.

44. Calle EE, Rodriguez C, Walker-Thurmond K, Thun MJ. Overweight, obesity, and mortality from cancer in a prospectively studied cohort of U.S. adults. N Engl J Med. 2003;348(17):1625-38.

45. Wolk A, Gridley G, Svensson M, Nyren O, McLaughlin JK, Fraumeni JF, et al A prospective study of obesity and cancer risk (Sweden). Cancer Causes Control. 2001;12(1):13-21.

46. Møller H, Mellemgaard A, Lindvig K, Olsen JH. Obesity and cancer risk: a Danish record-linkage study. Eur J Cancer. 1994;30A:344-50.

47. Neuschwander-Tetri BA, Caldwell SH. Nonalcoholic steatohepatitis: Summary of an AASLD Single Topic Conference. Hepatology. 2003;37(5):1202-19.

48. El-Serag HB, Mason AC. Rising incidence of hepatocellular carcinoma in the United States. N Engl J Med. 1999;340:745-50.

\section{Submit your next manuscript to BioMed Central and take full advantage of:}

- Convenient online submission

- Thorough peer review

- No space constraints or color figure charges

- Immediate publication on acceptance

- Inclusion in PubMed, CAS, Scopus and Google Scholar

- Research which is freely available for redistribution 